\title{
PELATIHAN SENAM LANSIA SEBAGAI UPAYA PENINGKATAN KUALITAS HIDUP DI MASA MENOPAUSE DI WILAYAH KERJA PUSKESMAS LEBAK BULUS
}

\author{
Isroni Astuti $^{\circledR}$, Mumun Munigar² \\ Coreponding author: isronie_astutie@yahoo.com \\ 1,2 Jurusan Kebidanan, Poltekkes Kemenkes Jakarta I, Indonesia
}

Genesis Naskah: Submitted: 02-11-2021, Revised: 01-12-2021, Accepted: 02-12-2021

\begin{abstract}
Abstrak
Lansia merupakan salah satu kelompok penduduk yang potensial menjadi masyarakat rentan, sehingga perlu diciptakan suatu kondisi fisik maunpun non fisik yang kondusif untuk pembinaan kesejahteraannya. Salah satu senam untuk menjaga kesehatan lansia yang paling murah dan mudah dilakukan adalah senam bugar lansia. Program kegiatan peningkatan kualitas hidup lansia ini tidak akan berjalan dengan baik tanpa adanya dukungan dan partisipasi yang baik dari lansia itu sendiri, dukungan penuh yang diberikan oleh keluarga maupun masyarakat. Kegiatan dilakukan secara berkala dan berkesinambungan sesuai jadwal kegiatan, melalui sarana kegiatan belajar bersama dalam bentuk tatap muka dalam kelompok, penyuluhan diberikan, pemberian materi, pemutaran video, pelatihan senam dan diskusi tentang senam lansia pada wanita menopause. Setelah dilaksanakan pendidikan kesehatan dan pelatihan tentang senam bugar lansia pada ibu menopause didapatkan hasil tejadi peningkatan skor pengetahuan dari nilai rerata dari pelaksaaan pretest adalah 61.8 menjadi 80.00 pada posttest, terjadi kenaikan 14 poin skor. Semua ibu menopause sudah mendapatkan pelatihan senam bugar lansia.
\end{abstract}

\section{Kata Kunci : Senam Lansia, Kualitas Hidup, Menopouse \\ ELDERLY GYMNASTICS TRAINING AS A QUALITY OF LIFE IMPROVEMENT MENOPAUSE WOMEN IN LEBAK BULUS PRIMARY HEALTH CARE}

\begin{abstract}
Background: The elderly are one of the population groups that have the potential to become vulnerable people, so it is necessary to create a conducive physical and non-physical condition for fostering their welfare. The Ederly Gymnastics to maintain the health of the elderly that is the cheapest and easiest to do is fitness for the elderly. This program of activities to improve the quality of life of the elderly will not run well without good support and participation from the elderly themselves, the full support provided by the family and the community. Method: Activities are carried out regularly and continuously according to the schedule of activities, through the means of group learning activities in the form of face-to-face in groups, counseling is given, material provision, elderly gymnastics video, gymnastics training and discussions about elderly exercise in menopausal women. Results: After conducting health education and training on fitness for the elderly in menopausal women, it was found that there was an increase in the knowledge score from the mean value of the pretest implementation from 61.8 to 80.00 in the posttest, an increase of 14 score points. All postmenopausal women have received gymnastiscs, training for the elderly.
\end{abstract}

Keywords:. Elderly Gymnastics, Quality of Life, Menopause 


\section{Pendahuluan}

Kementrian Sosial menyatakan jumlah lanjut usia (lansia) di Indonesia lebih dari 10\% dari populasi penduduk pada 2020. Pada tahun 2020 jumlah penduduk di Tanah Air mencapai 269,9 juta orang dengan jumlah penduduk usia di atas 60 tahun mencapai 28,7 juta orang. Artinya, lebih dari 10,6\% jumlah penduduk Indonesia merupakan lansia. Persentase penduduk lansia dikatakannya terus meningkat hingga $16,5 \%$ pada 2035. Indonesia akan mengalami fenomena feminisasi lansia. Ini merupakan suatu kondisi di mana jumlah lansia perempuan lebih banyak dibandingkan lansia laki-laki. Untuk mengantisipasi peningkatan jumlah lansia setiap tahun, diperlukan beberapa upaya. Peningkatan kualitas dan kuantitas program pelayanan sosial bagi lansia untuk melindungi dari berbagai risiko penuaaan (Pertiwi, 2020).

Penduduk lansia merupakan salah satu kelompok penduduk yang potensial menjadi masyarakat rentan, sehingga perlu diciptakan suatu kondisi fisik maunpun nonfisik yang kondusif untuk pembinaan kesejahteraannya. Pada hakikatnya, kaum lansia di berbagai negara termasuk Indonesia tidak hanya diharapkan berumur panjang, namun juga dapat menikmati masa tuanya dengan sehat, bahkan berdayaguna bagi pembangunan. Oleh karena itu perlu suatu strategi khusus untuk meangani mereka sejak dini (Nugraheni \& Hardini, 2017).

Olahraga berperan dalam meningkatkan kesehatan jasmani, salah satu manfaat olahraga adalah melancarkan sirkulasi darah, memperkuat otot, mencegah pengeroposan tulang, menurunkan tekanan darah, menurunkan kolesterol jahat, dan menaikkan kolesterol baik. Olahraga juga bermanfaat untuk membakar kalori, meningkatkan keseimbangan dan koordinasi otot dan meningkatkan kekebalan tubuh. Olahraga sangat baik dilakukan terutama oleh lansia agar aliran darah menjadi lancar, salah satu olahraga yang baik dilakukan oleh lansia adalah senam lansia. Pada usia lanjut kekuatan mesin pompa jantung berkurang. Berbagai pembuluh darah penting khusus di jantung dan otak mengalami kekakuan, dengan latihan fisik atau senam dapat membantu kekuatan pompa jantung agar bertambah, sehingga aliran darah bisa kembali lancar. Jika dilakukan secara teratur akan memberikan dampak yang baik bagi lansia terutama terhadap tekanan darahnya (Wulandari \& Marliana, 2019).

Salah satu senam untuk menjaga kesehatan lansia yang paling murah dan mudah dilakukan adalah senam bugar lansia. Dengan melakukan olahraga seperti senam lansia dapat mencegah atau melambatkan kehilangan fungsional tersebut. Bahkan dari berbagai penelitian menunjukkan bahwa latihan seperti senam lansia dapat mengeliminasi berbagai resiko penyakit seperti peningkatan tekanan darah, diabetes mellitus, penyakit arteri koroner dan kecelakaan. Senam lansia yang dilakukan secara teratur dapat meningkatkan pemenuhan kebutuhan tidur. Frekuensi latihan yang berguna untuk mempertahankan dan memperbaiki kesegaran jasmani lansia dilakukan sedikitnya satu minggu sekali dan sebanyak-banyaknya lima kali dalam satu minggu dengan lamanya 15 menit (Maryam, 
2008). Meskipun senam bugar lansia sangat murah dan mudah dilakukan, tetapi masih banyak lansia yang melakukan senam secara teratur. Kurangnya informasi dan pengetahuan yang dimiliki oleh lansia maupun keluarga yang memiliki lansia menjadi salah satu penyebabnya (Ni Putu Dewi Sri Wahyuni, 2015).

Sindrom menopause berdampak pada penurunan kualitas hidup pada masa menopause. Sangat diperlukan persiapan menjelang menopause berupa dukungan sosial, kepercayaan diri dan sikap positif terhadap keluhan yang dialami sehingga wanita dapat menerima menopause sebagai karunia karena bersifat normal. Senam aerobic yang dilakukan dengan benar dapat memberi manfaat bagi kebugaran jasmani. Senam aerobik low impact berpengaruh terhadap pengurangan keluhan vasomotorik, keluhan psikis dan keluhan somatik pada pre menopause (Sasnitiari, 2018).

Upaya mewujudkan peningkatan hidup lansia yang sehat, produktif, mandiri serta berkualitas harus dilakukan pembinaan sedini mungkin selama siklus kehidupan manusia, dapat dilakukan dengan berbagai kegiatan diantaranya kegiatan-kegiatan yang dapat memacu lansia untuk beraktifitas serta meningkatkan kesadaran lansia tentang pola hidup sehat dengan asupan gizi yang sehat. Program kegiatan peningkatan kualitas hidup lansia ini tidak akan berjalan dengan baik tanpa adanya dukungan dan partisipasi yang baik dari lansia itu sendiri. Untuk itu adanya perawatan dan dukungan penuh yang diberikan oleh keluarga maupun masyarakat sekitar maka akan menambah kualitas hidup lansia menuju lansia yang produktif dan mandiri (Sulistyowati, 2020).

\section{Metode Pelaksanaan}

Bentuk realisasi kegiatan dilaksanakan dalam bentuk pengabdian kepada masyarakat selama 6 bulan melalui tahapan persiapan, pelaksanaan, monitoring, dan evaluasi program dengan rincian sebagai berikut :

\section{Persiapan}

a. Menyusun proposal pengabdian masyarakat tentang pelatihan senam lansia sebagai upaya peningkatan kualitas hidup di masa menopause di wilayah kerja puskesmas lebak bulus.

b. Mengikuti review proposal pengabdian kepada masyarakat oleh reviewer Poltekkes Kemenkes Jakarta I.

c. Melakukan survey tempat Pengabdian masyarakat.

d. Mengurus perijinan.

e. Melakukan koordinasi pihak terkait di wilayah Puskesmas Lebak Bulus dan penanggung jawab berserta kader posyandu lansia.

f. Mempersiapkan bahan dan materi penyuluhan berupa: materi penyuluhan, leaflet, form evaluasi pre test dan post test, dan video senam lansia kemenpora.

\section{Pelaksanaan}

Pada tahapan pelaksanaan kegiatan dilakukan kegiatan sebagai berikut :

a. Pretest, untuk mengetahui pengetahuan dan ketrampilan awal ibu menopause di Posyandu Lansia Kasih Ibu RW IV Kelurahan Lebak Bulus. 
b. Pelaksanaan Pendidikan Kesehatan dan pelaksanaan pelatihan senam lansia di Posyandu lansia Kasih Ibu RW IV Kelurahan Lebak Bulus.

c. Post test, untuk mengetahui pengetahuan dan ketrampilan awal ibu menopause di Posyandu Lansia Kasih Ibu RW IV Kelurahan Lebak bulus

\section{Monitoring}

a. Monitoring pada kegiatan pengabmas dengan membuat laporan kemajuan pengabdian masyarakat.

b. Pelaksanaan monitoring melibatkan kader posyandu Lansia Kasih Ibu RW IV kelurahan lebak bulus

\section{Evaluasi}

a. Evaluasi kegiatan penilaian pengabdian masyarakat dilaksanakan dengan menganalisis hasil kuesioner dari pre test dan post test

b. Evaluasi lisan dengan menggunakan dengar pendapat bersama lansia dan kader posyandu Lansia Kasih Ibu RW IV kelurahan lebak bulus

\section{Hasil dan Pembahasan}

Tabel 1 Hasil Nilai Pretes dan Post Test ibu Menopause Di Posyandu Kasih Ibu RW IV Keluarahan Lebak Bulus

\begin{tabular}{cccc}
\hline No & Nama & $\begin{array}{c}\text { Skor Nilai } \\
\text { Pre-test* }\end{array}$ & $\begin{array}{c}\text { Skor Nilai } \\
\text { Post Test** }\end{array}$ \\
\hline 1 & Responden 1 & 66 & 86 \\
\hline 2 & Responden 2 & 54 & 74 \\
\hline 3 & Responden 3 & 60 & 80 \\
\hline 4 & Responden 4 & 70 & 90 \\
\hline 5 & Responden 5 & 46 & 68 \\
\hline 6 & Responden 6 & 62 & 70 \\
\hline 7 & Responden 7 & 54 & 78 \\
\hline 8 & Responden 8 & 70 & 82 \\
\hline 9 & Responden 9 & 72 & 92 \\
\hline 10 & Responden 10 & 52 & 66 \\
\hline
\end{tabular}

\begin{tabular}{cccc}
\hline No & Nama & $\begin{array}{c}\text { Skor Nilai } \\
\text { Pre-test* }\end{array}$ & $\begin{array}{c}\text { Skor Nilai } \\
\text { Post Test** }\end{array}$ \\
\hline 11 & Responden 11 & 60 & 78 \\
\hline 12 & Responden 12 & 72 & 98 \\
\hline 13 & Responden 13 & 78 & 88 \\
\hline 14 & Responden 14 & 60 & 72 \\
\hline 15 & Responden 15 & 62 & 74 \\
\hline 16 & Responden 16 & 56 & 68 \\
\hline 17 & Responden 17 & 60 & 72 \\
\hline 18 & Responden 18 & 56 & 68 \\
\hline 19 & Responden 19 & 60 & 80 \\
\hline 20 & Responden 20 & 62 & 82 \\
\hline 21 & Responden 21 & 64 & 88 \\
\hline 22 & Responden 22 & 66 & 92 \\
\hline 23 & Responden 23 & 70 & 88 \\
\hline 24 & Responden 24 & 56 & 74 \\
\hline 25 & Responden 25 & 60 & 76 \\
\hline 26 & Responden 26 & 70 & 90 \\
\hline 27 & Responden 27 & 72 & 90 \\
\hline 28 & Responden 28 & 50 & 72 \\
\hline 29 & Responden 29 & 54 & 78 \\
\hline 30 & Responden 30 & 60 & 88 \\
\hline Ket : * Belum Pernah Senam Lansia, & \\
$* *$ Sudah Melakukan Senam Lansia & \\
\hline & & & \\
\hline
\end{tabular}

Dari hasil pre test di dapatkan bahwa nilai rerata dari pelaksaaan pre test adalah 61.8. Untuk nilai tertinggi yang dapatkan pada kegiatan pre test adalah 72 dan nilai terendah yang didapatkan adalah 46. Maka dapat dikatakan pengetahuan ibu-ibu menopause di posyandu Kasih Ibu RW IV kelurahan Lebak Bulus masih kurang.

Dari hasil kuesioner pada pretest didapatkan bahwa semua ibu di posyandu belum pernah melaksanakan senam lansia bugar lansia Kemenpora. Ibu-ibu menopouse di posyandu lansia tersebut hanya melaksanakan senam otak apabila ada kegiatan posyandu lansia di wilayah yaitu setiap 1 bulan sekali, pada minggu ke tiga.

Dari hasil post test di dapatkan bahwa nilai rerata dari pelaksaaan post test adalah 80 . Untuk nilai tertinggi yang dapatkan pada kegiatan pre test adalah 98 dan nilai terendah yang didapatkan adalah 80. Maka dapat setelah dilakukan pelatihan senam lansia pengetahuan ibu-ibu 
menopause meningkat dan mempunyai pengetahuan baik di posyandu Kasih Ibu RW IV kelurahan Lebak Bulus. Terjadi peningkatan sebelum dan sesudah post test sebanyak 14 poin skor.

Setelah di lakukan pelatihan senam bugar lansia (SBL) di Posyandu Kasih Ibu, Ibu-ibu menopouse di posyandu lansia tersebut sudah mengenal dan melaksanakan senam bugar lansia. Hasil evaluasi secara lisan ibu-ibu merasa senang dan ingin bisa melakukan senam lansia. Berdasarkan kesepakatan pengurus, kader dan ibu-ibu menopause di posyandu lansia di posyandu Kasih Ibu RW IV kelurahan Lebak Bulus merencanakan akan mengadakan senam lansia secara rutin dengan mengundang instruktur senam, senam direncanakan akan dilakukan setiap minggu sekali di hari Sabtu secara rutin.

\section{Kesimpulan dan Saran}

Setelah dilaksanakan pendidikan kesehatan tentang senam bugar lansia pada ibu menopause di Posbindu Lansia Kasih ibu-ibu menopause di RW IV di kelurahan Lebak Bulus di dapatkan hasil tejadi peningkatan skor pengetahuan dari nilai rerata dari pelaksaaan pretest adalah 61.8 menjadi 80.00 pada posttest, terjadi kenaikan 14 poin skor.

Semua ibu menopause di Posbindu lansia kasih ibu-ibu menopause di RW IV di kelurahan Lebak Bulus sudah mendapatkan peltihan senam bugar lansia kemenpora.

Hasil evaluasi secara lisan ibu-ibu ibu-ibu menopause RW IV di kelurahan Lebak Bulus merasa senang dan ingin bisa melakukan senam lansia secara rutin.
Ibu-ibu menopause di posyandu lansia di posyandu Kasih Ibu RW IV kelurahan Lebak Bulus akan mengadakan senam lansia secara rutin dengan mengundang instruktur senam, senam direncanakan akan dilakukan setiap minggu sekali di hari Sabtu. Adapun saran yang didapatkan adalah penyuluhan kesehatan tentang senam lansia perlu diberikan di setiap posbindu lansia dan perlu dimasukan pelatihan senam bugar lansia kemenpora pada setiap posbindu lansia.

\section{Daftar Pustaka}

Maryam, S. (2008). Mengenal Usia Lanjut dan Perawatannya. Salemba Medika.

Ni Putu Dewi Sri Wahyuni. (2015). Lansia Sehat Dan Bahagia Dengan Senam Bugar Lansia. Proceedings Seminar Nasional FMIPA UNDIKSHA V Tahun 2015.

Nugraheni, R., \& Hardini, K. F. (2017). Pengabdian Masyarakat "Penyuluhan Lansia Sehat Dan Mandiri" Dan "Senam Lansia Untuk Mencegah Low Back Pain." ... Pengabdian Masyarakat, 42-46.

https://prosidingonline.iik.ac.id/index.php/senias /article/view/34

Pertiwi, S. W. P. (2020). Tahun Ini, Jumlah Lansia 10,6\% dari Populasi Indonesia. Media Indonesia.

https://mediaindonesia.com/humaniora/346598/t ahun-ini-jumlah-lansia-106-dari-populasiindonesia

Sasnitiari, S. M. N. N. (2018). Pengaruh Senam Aerobik Low Impac terhadap Pengurangan Keluhan Ibu Premenopause di Wilayah Puskesmas Merdeka Bogor Tahun 2016. Jurnal Bidan, IV(1).

Sulistyowati, E. T. (2020). Peningkatan kualitas hidup lansia dengan senam lansia dan penyuluhan tentang menu sehat lansia di asrama polisi pingit. Jurnal Pengabdian Masyarakat Karya, 2(1), 3540.http://jurnal.poltekkeskhjogja.ac.id/index.php /jpmkh/article/view/387

Wulandari, S. T., \& Marliana, Y. (2019). Senam Kebugaran Lansia Memengaruhi Tekanan Darah Pada Wanita Menopause. Jurnal Kesehatan Prima, 13(1), 18. https://doi.org/10.32807/jkp.v13i1.216 